\title{
VALIDAÇÃO DE JOGOS EDUCATIVOS EM FARMACOLOGIA
}

\section{VALIDATION OF EDUCATIONAL GAMES IN PHARMACOLOGY}

\author{
Karla Meira Castro Zepponi ${ }^{1}$ \\ Luzmarina Aparecida Doretto Braccialli ${ }^{2}$ \\ Osni Lazaro Pinheiro ${ }^{3}$
}

\begin{abstract}
Resumo: Introdução A utilização de tecnologia educacional, por meio de estratégia lúdica, pode facilitar a aprendizagem dos estudantes. Objetivo: Construir dois jogos para ser aplicado aos estudantes do Curso Técnico de Farmácia de uma Instituição de Ensino Pública e validá-los por juizes da área de Farmacologia e Educação. Método É um estudo descritivo, observacional e qualitativo, com coleta de dados subtraída da avaliação de quatro juízes da área de Farmacologia e quatro da área da Educação. Os jogos foram validados e enriquecidos com o preenchimento de observações colocadas pelos juízes. Estes instrumentos foram reorganizados, formando núcleos de sentido fomentando uma análise de conteúdo por modalidade temática. Resultados Evidenciou-se duas categorias temáticas: Benefícios dos jogos na aprendizagem e Os cuidados com conteúdos e regras na busca pela aprendizagem por meio de jogos. Conclusões Os apontamentos feito pelo juízes trouxeram uma proposta mais dinâmica e propositiva para o aprendizado por meio dos jogos.
\end{abstract}

Palavras-chave: Aprendizagem; Ensino; Jogo; Material Didático.

Abstract: Introduction The use of educational technology, through a playful strategy, can facilitate student learning. Objective To build two games to be applied to students of the Pharmacy Technical Course of a Public Education Institution and to validate them by judges in the area of Pharmacology and Education. Method This is a descriptive, observational and qualitative study, with data collection subtracted from the evaluation of four judges from the Pharmacology area and four from the Education area. The games were validated and enriched by filling in observations placed by the judges. These instruments were reorganized, forming nuclei of meaning, fostering a content analysis by thematic modality. Results Two thematic categories were evidenced: Benefits of games in learning and Care with contents and rules in the search for learning through games. Conclusions The notes made by the judges brought a more dynamic and purposeful proposal for learning through games.

Keywords: Learning; Teachin; Game; Teaching Material.

\section{Introdução}

O Ensino Técnico Profissionalizante apresenta um grande desafio para os docentes, que é trazer a proximidade com o mercado de trabalho dentro de sala de aula.

\footnotetext{
${ }^{1}$ Mestrado em Educação em Saúde pela Faculdade de Medicina de Marília (FAMEMA). Docente da Escola Técnica Estadual (ETEC), Araçatuba, São Paulo, Brasil. E-mail: ka.zpp@ hotmail.com

${ }^{2}$ Doutorado em Ciências na Escola De Enfermagem Universidade de São Paulo (EEUSP). Docente na Faculdade de Medicina de Marilia (FAMEMA), Marília, São Paulo, Brasil. E-mail: luzbra@ terra.com.br

${ }^{3}$ Doutorado em Ginecologia, Obstetrícia e Mastologia na Universidade Julio de Mesquita (UNESP), Docente na Faculdade de Medicina de Marilia (FAMEMA), Marília, São Paulo, Brasil. E-mail: osnilp@terra.com.br
} 
Entre esses desafios estão o rompimento de paradigmas dos ensinos tradicionais e trabalhar com os estudantes os desenvolvimentos de estudos voltados para a saúde e os cuidados com os seres humanos (CRISTINE, 2013).

A terapia medicamentosa na qual envolve aquisição, distribuição e todo o processo de preparo de medicamentos, esta totalmente inserida na ementa do Curso Técnico em Farmácia e consequentemente manipulações de fórmulas, seu mecanismo de ação e a farmacocinética. Desta forma, torna-se pertinente ter um olhar mais assistido para a disciplina de Farmacologia, na qual apresenta conteúdos bastante complexos (CONSELHO FEDERAL DE FARMÁCIA, 2002).

Juntando a complexidade da Farmacologia, com a importância na formação profissional, pensou-se em uma estratégia de ensino voltadas para jogos. Essa possibilita conhecimento dentro desta formação, pensou-se em uma estratégia de ensino voltadas para jogos. Pensando em tornar o estudante protagonista em sua formação e conhecimento em sala de aula (SERIACOPI, 2006).

\section{1 Formação do Técnico em Farmácia}

As Diretrizes Curriculares Nacionais (DCN) pela Resolução $\mathrm{n}^{\circ}$ 6, de 20 de setembro de 2012, norteia a Educação Profissional Técnica de Ensino Médio (MINISTÉRIO DA EDUCAÇÃO, 2013).

O Curso Técnico em Farmácia traz a formação profissional, oferecendo ao mercado profissionais mais preparados, criativos e com senso crítico, que possam atuar em diferentes cenários, tomar decisões, fazendo um diferencial na profissão (CONSELHO FEDERAL DE FARMÁCIA, 2016).

Sua atuação é na área da saúde, manipulação de medicamentos, dispensação, indústrias, insumos e correlatos (CONSELHO FEDERAL DE FARMÁCIA, 2016).

Devido a grande importância da profissão acha-se pertinente conhecer mais agentes farmacológicos disponíveis no mercado, seus mecanismos de ação e sua farmacocinética, os conhecimentos básicos de Farmacologia são imprescindíveis para o Técnico de Farmácia.

\section{2 A Farmacologia e o Técnico de Farmácia}

A Farmacologia e a indústria farmacêutica desenvolvem grandes parcerias. Seu estudo foi incorporado nas instituições na área da saúde no século XX. Sua atuação 
relaciona-se com interações de agente químico e orgânico, podendo causar bem ou mal para os pacientes como os efeitos colaterais (BRUNTON; HILAL-DANDAN; KNOLLMANN, 2018; RANG et al., 2016).

\section{3 Jogos para o ensino e aprendizagem}

Os estudantes que iniciam o ensino técnico, querem um imediatismo no aprendizado para estarem aptos ao mercado de trabalho, o desenvolvimento de jogos, pode trazer esta aproximação, quando os conteúdos são bem estabelecidos e trabalhados.

O uso de jogos na aprendizagem pode proporcionar entendimentos que os materiais didáticos tradicionais não alcançam. Essa dificuldade faz com que os professores tenham que elaborar aulas mais criativas e capazes de despertar a atenção dos seus estudantes. Para isso, podem empregar a diversidade dos recursos tecnológicos atualmente existentes, inclusive as informações do mundo virtual (MORAN, 2000).

O professor, por sua vez, diante da educação contemporânea, a qual preconiza formar o profissional humanizado, ético e reflexivo acerca da realidade da população, deve trabalhar com conteúdos significativos, que abordem situações-problema, a fim de despertar interesse dos estudantes e, com isso, trazer a percepção de suas responsabilidades enquanto profissionais, por meio de articulações entre teoria e prática. (GHEZZI et al., 2018).

\section{Metodologia}

O presente estudo é uma investigação descritiva e observacional, na qual a coleta de dados foi feita de forma prospectiva. O estudo foi aprovado pelo Comitê de Ética em Pesquisa Envolvendo Seres Humanos de um Instituição Pública do Estado de São Paulo. A pesquisa envolve a validação de dois jogos, sendo um jogo de tabuleiro e outro envolvendo peças que se encaixam para o aprendizado do conteúdo básico de Farmacologia. O grupo de autores selecionaram por meio de uma reunião quais seriam as melhores opções de jogos, associado a buscas em bases de dados para então concretizar a construção dos jogos.

O conteúdo de Farmacologia foi abordado em linguagem condizente com as necessidades de estudantes de curso técnico, com clareza na redação, articulação de situações vivenciadas na prática profissional do técnico farmacêutico, propiciando o raciocínio dos estudantes. 
A Farmacologia é uma disciplina muito complexa, a disciplina no Curso Técnico em Farmácia é dividida em dois módulos, trazendo assuntos como citadas no quadro abaixo:

Quadro 1: Ementa das disciplinas de Farmacologia I e II do Curso Técnico em Farmácia

\begin{tabular}{|c|c|c|}
\hline Módulo & \multicolumn{2}{|r|}{ Bases Tecnológicas } \\
\hline \multirow{8}{*}{ 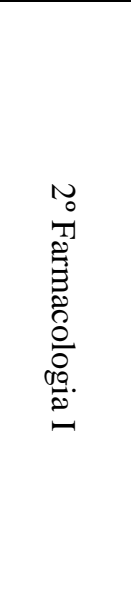 } & Farmacocinética & Absorção, distribuição, metabolismo e excreção \\
\hline & Farmacodinâmica & Tipos de receptores: agonistas e antagonistas \\
\hline & Interações medicamentosas & Fisicoquímica, farmacocinética e farmacodinâmica \\
\hline & $\begin{array}{l}\text { Reações adversas a } \\
\text { medicamentos (RAM) }\end{array}$ & Classificação \\
\hline & $\begin{array}{l}\text { Medicamentos que agem } \\
\text { sobre os diversos sistemas } \\
\text { do organismo }\end{array}$ & $\begin{array}{l}\text { Antibióticos, antifúngicos, antivirais, sulfonamidas, } \\
\text { antineoplásicos, antirreumáticos, corticoides e } \\
\text { antigotosos }\end{array}$ \\
\hline & $\begin{array}{l}\text { Medicamentos que } \\
\text { interferem no metabolismo e } \\
\text { nutrição }\end{array}$ & $\begin{array}{l}\text { Anorexígenos, estimulantes do apetite, } \\
\text { antilipemiantes, sais minerais e vitaminas }\end{array}$ \\
\hline & $\begin{array}{l}\text { Medicamentos que atuam no } \\
\text { sistema endócrino }\end{array}$ & Hipoglicemiantes, contraceptivos e hormônios \\
\hline & $\begin{array}{l}\text { Medicamentos que atuam no } \\
\text { sistema hematopoiético }\end{array}$ & $\begin{array}{l}\text { Antianêmicos, anticoagulantes, antiagregantes, } \\
\text { plaquetários e coagulantes }\end{array}$ \\
\hline & $\begin{array}{l}\text { Medicamentos que atuam no } \\
\text { sistema circulatório }\end{array}$ & $\begin{array}{l}\text { Anti-hipertensivos, vasodilatadores, antiarrítmicos, } \\
\text { cardiotônicos e diurético }\end{array}$ \\
\hline 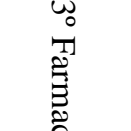 & $\begin{array}{l}\text { Medicamentos que atuam no } \\
\text { sistema digestório }\end{array}$ & $\begin{array}{l}\text { Antiácidos, antieméticos, antidiarreicos, } \\
\text { bloqueadores da secreção gástrica, laxativos e } \\
\text { purgativos }\end{array}$ \\
\hline 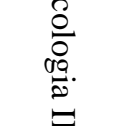 & $\begin{array}{l}\text { Medicamentos que atuam no } \\
\text { sistema nervoso central }\end{array}$ & $\begin{array}{l}\text { Analgésicos, antitérmicos, anti-inflamatórios, } \\
\text { corticoides, hipnóticos, ansiolíticos, antidepressivos, } \\
\text { neurolépticos e sedativos }\end{array}$ \\
\hline & $\begin{array}{l}\text { Medicamentos que atuam no } \\
\text { sistema respiratório }\end{array}$ & $\begin{array}{l}\text { Broncodilatadores, expectorantes, mucolíticos, } \\
\text { antitussígenos e anti-histamínicos }\end{array}$ \\
\hline
\end{tabular}
Fonte: (ZEPPONI, 2020)

Os jogos foram pensados e desenvolvidos, buscando facilitar o processo de aprendizagem. O jogo Tabuleiro do Conhecimento Conhecimento foi desenvolvido com cores, tamanhos, para proporcionar a leveza do universo lúdico associado a um assunto sério que será utilizado em sua profissão que é voltada para os cuidados do ser humano.

O jogo foi confeccionado na medida de $70 \times 50 \mathrm{~cm}$ em (MDF), os pinos foram feitoss em impressora 3D, polímero biodegradável, medindo de $3 \times 1 \mathrm{~cm}$ e o dado de borracha, com os números coloridos. As cartas impressas em gráfica e o conteúdo das cartas impresso em papel sulfite (Figura 1). 
Figura 1: Jogo "Tabuleiro do Conhecimento"

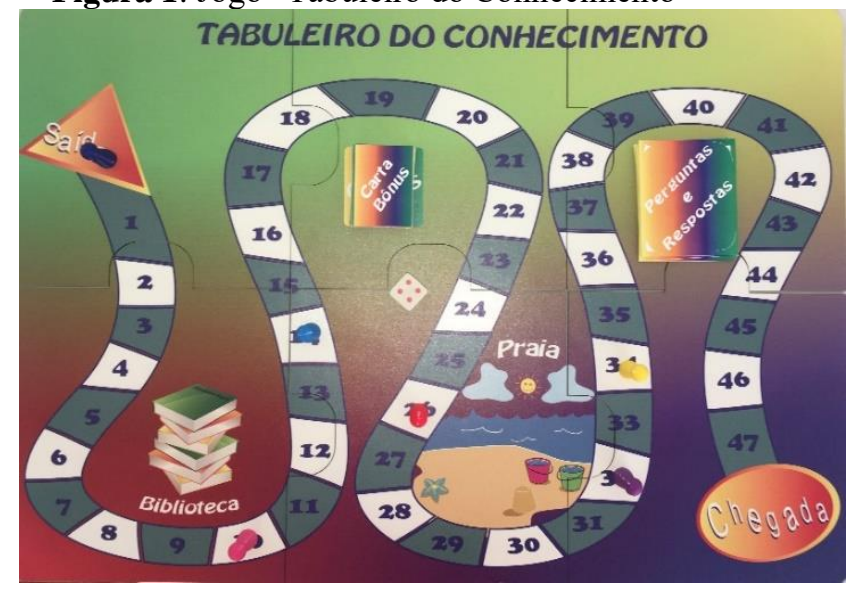

Fonte: (ZEPPONI, 2020)

O jogo Pense e Encaixe, foi criado especificamente para os estudantes se aproximarem mais dos conceitos de agonismo e antagonismo, consiste na interpretação de questões. Foi elaborado em MDF, com nove peças circulares de $10 \mathrm{~cm}$ diâmetro, em cores amarelas e azuis, uma peça com encaixes (Figura 2).

Figura 2: Jogo "Pense e Encaixe"

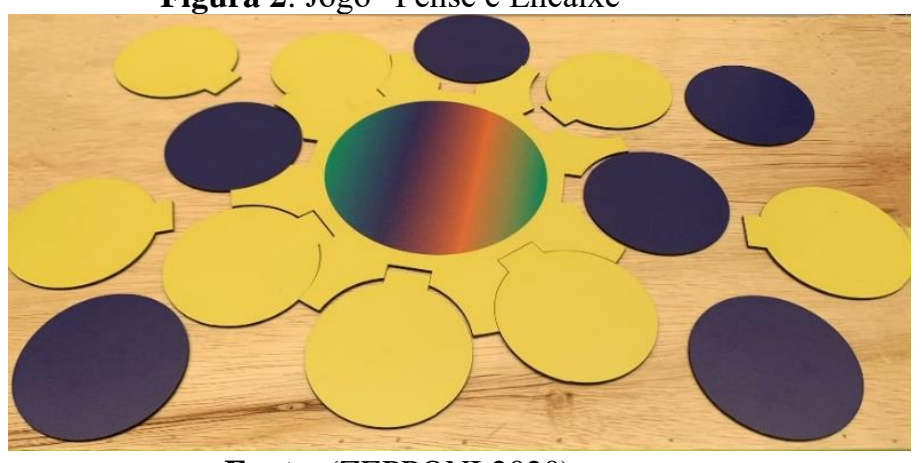

Fonte: (ZEPPONI,2020)

Em ambos os jogos foram criadas regras para o bom desempenho e dinamismo do jogo.

Após a confecção dos jogos, foi realizada a validação desse material lúdico/didático por um painel composto por dois grupos de juízes com expertises em Farmacologia $(n=4)$ e Educação $(n=4)$.

Os jogos foram validados após os juízes da área de Farmacologia receberem um questionário para avaliarem objetivo e conteúdo, Relevância dos jogos e os juízes da área de Educação avaliaram Estrutura, organização e ludicidade, ao final, para ambos os questionários continham campos abertos para que os juízes pudessem opinar (PIRES et al., 2015).

Os juízes foram identificados por códigos alfanuméricos “J” de 1 a 8. 
Os dados qualitativos foram resultantes dos campos abertos foram avaliados pela técnica de análise de conteúdo, modalidade temática. A análise de conteúdo deriva de caracteristícas que são citadas com frequência, desta forma, examina-se as escritas, a comuncação para se obter indicadores para inferência dos conteúdos relatados nos comentários (BARDIN, 2012; MINAYO; DESLANDES; GOMES, 2016). A busca por correlações entre palavras, frases é a fase precurssora para se fazer uma análise temática e consequentemente identificar núcleos de sentido, esta repetição de ideias traz um significado. O método deste estudo foi por meio de uma leitura minuciosa do material, na qual buscou-se uma classificação de frases e palavras que culminam em um mesmo sentido e depois categorizadas, formando núcleos de sentido (MINAYO; DESLANDES; GOMES, 2016).

Desta forma houve uma interpretação das falas dos juízes, com maior objetividade.

A vivência, a ação e o senso comum, fazem parte da análise qualitativa e assim traz dialeto, compreensão e interpretação (MINAYO, 2012). Levando as diferentes maneiras de interpretação vistas por diferentes olhares.

As experiências vividas por cada indivíduo, fomentam uma interpretação única, na advem de experiências vividas dos fatos ocorridos. O senso comum advém do conhecimento adquirido por meio das experiências e vivências que conferem ao sujeito a possibilidade do agir, embasado em seus valores e pensamentos. A compreensão vem da junção desses fatores, propiciando um entendimento singular de cada situação, podendo trazer discordância diante de um fato analisado por vários indivíduos (MINAYO, 2012).

Este estudo teve a finalidade de encontrar informações relatadas pelos juízes, e cuidados para não haver nenhum tipo de contaminação ou interpretações errôneas, com o propósito de compilar os dados das frases e seguir uma ordenação (por meio de avaliações), sequentemente, classificações (apontamentos positivos e negativos) e só então, definir quais as modalidades temáticas serão abordadas dentro de cada aspecto relevante (MINAYO, 2014; MOREIRA et al., 2019). Obteve-se cautela para não descartar informações preciosas que permeiam comentários, a forma que é falado, o contexto empírico e desta forma buscou-se por meio de uma análise profunda e baseada em teorias, para construir um material fidedigno com dados coerentes e ricos (MINAYO, 2012). 


\section{Resultados e Discussão}

Os campos abertos contidos apo's os questionários, possibilitaram a construção de uma análise qualitativa, na qual foi ordenada por classificação e delas surgiram duas categorias temáticas: Benefícios dos jogos na aprendizagem na qual envolvia a aprendizagem do conteúdo, simplicidade na aplicação, desenvolvimento do raciocínio e a diversão e integração dos estudantes; e os cuidados com conteúdos e regras na busca pela aprendizagem por meio de jogos , que envolvia regras, elaboração de conteúdos, números limitados de participantes, competitividade.

\subsection{Benefícios dos jogos na aprendizagem}

Trazer estes conteúdos em um espaço de um ano, requer muita habilidade para fazer um compilado de informações necessárias para o bom desenvolvimento profissional dos estudantes. Desta forma, bucar o auxílio dos jogos, que traz a possibilidade da inserção de uma forma diferente de aprendizagem é muito pertinente. As falas dos juízes nas frases citadas abaixo relatam a importância dos jogos na aprendizagem:

\footnotetext{
"O jogo é simples e de fácil compreensão. Aborda adequadamente os conteúdos da disciplina, proporciona ao aluno um meio divertido e eficaz de aprendizado." (J5)

"A estratégia dos jogos para o ensino desses conteúdos é muito interessante." (J6)

"O jogo é bem interativo e traz questões relevantes quanto ao conteúdo de Farmacologia." (J7)

"O jogo é simples e possibilita aos jogadores mobilizarem os conhecimentos para responderem questões." (J4)

"O jogo contém informações importantes e cruciais. Além disso, as perguntas estão elaboradas com exemplos de pacientes ou situações possíveis de acontecerem no exercício de sua futura profissão. Ocorre uma mescla interessante desses exemplos reais com conteúdos teóricos.” (J5)

"Favorece a fixação do conteúdo." (J3)

“-A linguagem está adequada. Sempre é preciso considerar a quem se aplica. (J4)

"Tendo em vista que o objetivo do jogo é o aprendizado, a presença deste tipo de carta poderia fazer com que o jogador revisse algum conteúdo que ele inove a resposta ou oferecer uma chance de ele acertar uma resposta no futuro." (J5)
}

Há uma grande variação de modalidades de aprendizagem nestas áreas do conhecimento, todas elas com relevância, porém é frágil que somente uma modalidade trará benefício na aprendizagem (CONCEIÇÃO; MOTA; BARGUIL, 2020). A associação com diversas formas de ensinar agregam uma a outra. Trazer o conteúdo em sala de aula, e depois aplicar jogos com questões de raciocínio, parece ser uma boa estratégia para levar as habilidades e desenvolvimento de competência aos estudantes (ZEPPONI, 2020). 
O ensino ditado como tradicional, na transmissão de conteúdo simplesmente, ainda é muito utilizado, porém não favorece a aprendizagem, segundo Freire, 2016. A limitação da exposição do conteúdo pelo professor onde os estudantes apenas escutam, não traz muita eficiência e não desperta o interesse nos estudantes (CONCEIÇÃO; MOTA; BARGUIL, 2020) A aula tradicional, na qual o professor expõe o conteúdo e os estudantes somente escutam, é uma estratégia de ensino pouco eficiente e não mobiliza o interesse dos estudantes pelos conteúdos trabalhados. A proposta deste estudo, foi levar aos estudantes o conhecimento sobre farmacologia de uma forma simples e cotidiana, associando a profissão com a realidade, e depois com os conteúdos objetivos e bem elaborados nas questões dos jogos, trabalhar o raciocínio e a conexão de ideias.

"Gostei muito e me vejo usando em sala de aula. Os conteúdos são pertinentes" (J1)

"O conteúdo é pertinente, para esse jogo sugiro um moderador." (J3)

"O professor como mediador, poderá intervir para conhecer o que pensa o aluno, entender onde se apoia para elaborar a atividade ou jogar." (J4)

Conforme citação, situações voltadas ao cotidiano dos estudantes traz um envolvivento maior por parte deles (CONCEIÇÃO; MOTA; BARGUIL, 2020)

[...] pode facilitar o trabalho do profissional de educação, despertando o interesse da criança ou adolescente pelas atividades propostas. Podemos orientar um trabalho de maneia tal que os alunos possam utilizar esse espaço para algo que vai além dos momentos sem nada a fazer. Independente da faixa etária, sexo ou raça, os alunos adoram jogar, brincar e o fazem de maneira espontânea. Por que não canalizar toda essa vontade para algo maior? [...] temos nas atividades lúdicas com jogos mais possibilidades para organizar os conteúdos e contemplar objetivos que extrapolam o que está posto (SANTOS, 2014, p. 21).

Os jogos trazem características que devem ser bem definidas para que sua contribuição seja efetiva na aprendizagem, os jogos, além de trazer a diversão, também trabalha a concentração. Isso, devido a intencionalidade do professor na elaboração do material (CONCEIÇÃO; MOTA; BARGUIL, 2020).

Nas considerações da temática abaixo, serão feitas algumas considerações e readequações propostas acerca dos conteúdos. O jogo do Tabuleiro do conhecimento teve o conteúdo melhor trabalhados, com pesguntas para maior raciocínio, o jogo Pense e Encaixe, teve maiores reformulações. 


\section{2 Cuidados com conteúdos e regras na busca pela aprendizagem por meio de jogos}

Os jogos didátics auxiliam o professor no processo de ensino e aprendizagem. $\mathrm{O}$ recurso "jogo" conduz ao conteúdo específico e traz como resultado as ações lúdicas na obtenção de informações (KISHIMOTO, 2002; SANTOS et al., 2020).

As questões citadas abaixo, apresentando pontos negativos, relacionados a regras, melhor elaboração de conteúdo, só acrescentam para a elaboração deste trabalho, visto que com estes apontamentos, pode-se buscar melhorias.

\footnotetext{
"Acredito que o jogo insiste muito em trabalhar questões que não são centrais, que não são essenciais para o cotidiano (Ex.: conceito de farmácia, remédio etc.)." (J6)

"Material excelente, apresentação impecável, parabéns." (J2)

"Tamanho do jogo, em sala de aula é possível que para 10-12 jogadores seja necessário um tabuleiro maior." (J1)

"Não vejo que este jogo possa contribuir com o aprendizado do aluno sobre conceitos-chave em um assunto tão importante e complexo como agonismo/antagonismo.” (J5)

"Questões conceituais ao meu ver não são tão pertinentes. Tenho consciência que se trata de um curso técnico e não universitário, mas acredito ser possível avançar para questões de mais raciocínio." (J6)

"Algumas perguntas presentes no jogo das cartas do tabuleiro eu reavaliaria o conteúdo, cartas com possibilidade de respostas ambíguas, em outras não concordei com a resposta assinalada como correta." (J5)

"Existem alguns pontos em relação às perguntas e respostas apresentando imprecisões." (J6)

"Esse jogo não parece muito útil para despertar o raciocínio, antes, parece ser útil para 'construir' uma imagem da situação fármaco-receptor na cabeça dos estudantes." (J6)

"Algumas cartas a pergunta está com elaboração um pouco confusa."

Esses comentários foram agrupados entre o jogo Tabuleiro do Conhecimento e Pense e encaixe, ambos tiveram os conteúdos readequados, o primeiro com elaborações mais ricas, com a intencionalidade do raciocínio, tornando a proposta dos jogos pertinente e assertiva, o segundo, além de reformulação na estrutura e cores, também houve reformulação nas questões, que ainda continuaram na limitação de respostas de agonista e antagonista, no qual era o objetivo, visto a dificuldade que os estudates tem de visualizar este processo, mas foi criado pequenos casos, aonde os estudantes puderam usar o racícínio para a conclusão da resposta, podendo argumentar com os colegas, a linguagem de ambos foram mais claras e objetivas (ZEPPONI; BRACCIALLI; PINHEIRO, 2020)

As regras também passaram por reformulações (ZEPPONI, 2020)

\footnotetext{
“A maior parte das regras está clara, mas não como jogar; está um pouco confuso sobre as cartas bônus: três ficam com o jogador e as outras no monte? Mas em qual momento ele pegará estas? Correção de formatação e erros ortográficos nas regras é necessário.” (J2)
} 
“A regra não esclarece se os jogadores irão jogar juntos ou um de cada vez e, assim, não fica claro se essa potencialidade será desenvolvida. Na regra, poderia ser definido que, por exemplo, quatro jogadores, cada um com uma peça, deveriam, juntos, montar o quebra-cabeças justificando o que pensaram enquanto jogavam.” (J4)

"Fica implícito que a ida na biblioteca é uma forma de aquisição de conhecimento, da forma como está atualmente o aluno pode interpretar que ir à biblioteca é um castigo ou uma punição e não uma oportunidade de favorecimento posterior." (J5)

"Se um jogador tirar com maior frequência que os demais as cartas com 'ir a biblioteca', 'ir para praia' será retardado no percurso, não por desconhecer o conteúdo, mas por falta de 'sorte', mas o jogo torna possível chegar ao objetivo. (J4)

"O meu entendimento é o de que esse jogo é 'apenas' um quebra-cabeça, não fazendo desafio na construção de conhecimento.” (J7)

"Sugestão, as cores do MDF deveriam ser iguais às cores dos ímãs e, na minha interpretação, se o ímã verde corresponde à ação agonista, o MDF roxo (ou magenta) com círculo amarelo corresponde ao receptor, por que o antagonista está representado na mesma cor? Sugiro usar a cor vermelha para antagonista como metáfora a verde (siga, faz ação) e vermelho (não promove ação esperada), pensando no contexto de aprendizagem técnica.” (J8)

"Não consegui ver relevância nesse jogo, pois o mesmo, ao meu juízo, se restringe a ser apenas um quebra-cabeça." (J7)

- Aplicabilidade é muito simples, porque limita-se à montagem de um quebracabeça simples. (J4)

"Acredito que as peças, no caso a central, poderiam ser indicadas que é uma célula. É isso? O círculo amarelo no quebra-cabeça de MDF é o núcleo? Nos ímãs, o núcleo é o roxo? Também considero que a abordagem do jogo nas instruções deve ser informada. Acrescentar um item por exemplo, objetivos." (J2)

"Na regra não está claro como poderiam, os jogadores, colaborarem um com os outros, não há informação de que devem montar juntos ou um de cada vez." (J4)

"O jogo pode ser de menor tamanho." (J3)

Há, no manual, orientação de 'como jogar', explicita que é uma competição, mas não diz 'onde devo chegar', o que é o ponto final da atividade.” (J4)

"Poderia ser de menor proporção, para ter vários na sala em grupos pequenos." (J3)

"Dependendo do tempo prescrito para a aula ( $2 \mathrm{~h}$ e $5 \mathrm{~min}$.), este jogo pode ser muito rápido para os estudantes montarem os quebra-cabeças. Deve-se ter outra abordagem associada sobre agonistas e antagonistas para discutir com os alunos. Caso contrário, a proposta ficará enfraquecida." (J2)

"Jogos de fixação não são bons para criar um quebra-cabeças, não pode ser realizado de outra forma." (J4)

Após a remodulação e readequação os pontos positivos foram transformados claramente para positivos, visto a importância da validação e de uma segunda avaliação para readequações.

As sugestões foram adequadas com pertinência e com certeza puderam contribuir para o avanço na elaboração, reestruturação de conteúdos, regras e objetividade. (ZEPPONI, 2020) Após as readequações, os juízes fizeram novas avaliações, que culminaram nas seguintes falas nos campos abertos disponíveis ao final de cada questionário: 
"A mudança no jogo foi produtiva, as perguntas foram bem elaboradas, os exemplos claros." (J5)

"O "Pense e Encaixe" possui excelente potencial como ferramenta pedagógica, inclusive para outros cursos da área da saúde." (J1)

Umas das questões que preocuparam os juízes foram as questões que permeavam a memorização, porém, eram relacionadas aos conhecimentos prévios que obtiveram antes das aplicações dos jogos, ainda assim, acatando as sugestões, todas as questões foram revistas e melhoradas (ZEPPONI, 2020)

\begin{abstract}
Penso que as questões apenas de memorização podem não despertar tanto interesse." (J7)

"A memorização é parte do processo de aprendizagem e há nesse jogo dois fatores de interação cognitiva: a 'fixação' (memorização) dos nomes (antagonista e agonista) e a relação do nome com a imagem. Se o aluno tiver ou sentir-se mais confortável, na forma de aprender, ligando nome à imagem, poderá construir um ponto de ancoragem para os estudos e/ou explicações do professor." (J5)

"Fixação não é sinônimo de aprendizagem. O jogo possibilita que o aluno relacione os nomes (antagonista e agonista) à imagem, mas aprender seu conceito não está garantido nesse jogo. Também não é invalidada a possibilidade, mas não é garantia. O termo da questão é se o jogo 'visa' à aprendizagem e isso coloca essa possibilidade nas mãos (ou na intenção) do 'professor/pesquisador'. Todavia, aprender pressupõe considerar fatores do aluno, como, por exemplo, mobilizar conhecimentos para atingir um objetivo ou vencer/superar algum obstáculo e, nessa perspectiva, o jogo não garante que haverá aprendizagem.” (J4)
\end{abstract}

Há a preocupação de levar o aprendizado ativo e significativo sem o simples processo de decorar, memorizar (SANTOS et al., 2020).

A preocupação citada pela competição, deixa de ser uma preocupação, ao observar que as metodologias que envolvem competição, também promovem a atenção e concentração (SOUSA et al., 2020). A propostas de ter um vencedor, a competitividade, fomenta uma atenção especial, juntamente com o anseio por vencer, e querer fazer tudo certo (ZEPPONI; BRACCIALLI; PINHEIRO, 2020).

"Concordo que o jogo possa propiciar cooperação, mas não acredito ser salutar ao aprendizado e estímulo à competição, a não ser que essa seja bem discutida com os alunos. (J2)

"Não está explicitado qual objetivo, uma vez que se trata de uma competição." (J4)

Na aplicação dos jogos, conta-se com jogabilidade que é sinônimo de construção de conhecimento, interação e motivação por parte do estudante, organização, cumprimentos das regras, resolução de problemas, contudo, promove a disciplina (SERAFIM et al., 2019).

"Pergunta 10 promove disciplina? Em que sentido? De comportamento? Ou promove a disciplina de Farmacologia?” (J2) 
“Quanto à disciplina (questão 10), é possível promover a disciplina, no entanto, em se tratando de jogos que podem estimular um caráter competitivo, pode tornar-se difícil de manter a organização, respeito e disciplina dos estudantes." (J1)

No questionário houve uma questão: “O jogo promove a disciplina”, esta questão está relacionada à jogabilidade e à cumprimento de regras, respeito aos participantes do jogo, ética, que para serem respeitadas, devem estar ligados à disciplina. O processo de aprendizagem com os jogos traz conexões sociais, diferentes indíviduos participando de uma mesma questão (o aprender), essas pessoas possuem individualizades e se organizam de maneiras diferentes, então trabalhar a disciplina neste sentido é a questão. (ZEPPONI, 2020)

O universo lúdico prepara as pessoas para a sociedade, nelas estão inseridas regras coletivas e limites entre a vida real e a lúdica (FAETI; CALSA, 2015; ZEPPONI, 2020)

\section{Conclusão}

Os jogos elaborados para a aprendizagem de Farmacologia no Curso Técnico em Farmácia tiveram uma boa avaliação perante os juízes. Houve dois processos de validação, neles os apontamentos relatados pelos juízes trouxeram uma contribuição ímpar, tornando os jogos mais atrativos e permitindo assim que os estudantes façam uma viagem lúdica no processo de ensino e aprendizagem.

As modalidades temáticas selecionadas, abordaram os pontos positivos e negativos, e possibilitaram identificar as melhorias. Do ponto de vista da pesquisa, o trabalho tem muito a contribuir com o ensino, as estruturas podem futuramente serem adaptadas para outros conteúdos.

\section{Referências}

ASSIS, M. Uma nova sensibilidade nas práticas de saúde. Interface, Botucatu, v. 5, n. 8, p. 139-140, fev. 2001. Disponível em:

http://www.scielo.br/scielo.php?script=sci_arttext\&pid=S1414-

32832001000100014\&lng=en\&nrm=iso. Acesso em: 02 abr. 2021.

BARDIN, L. Análise de conteúdo. Edição 70 São Paulo, 2011.

BRASIL. MINISTÉRIO DA EDUCAÇÃO. Diretrizes curriculares nacionais para educação profissional técnica de nível médio. Brasília (DF): Ministério da Educação, 2013.

BRUNTON, L. L.; HILAL-DANDAN, R. KNOLLMANN, B. C. As bases farmacológicas da terapêutica de Goodman \& Gilman. 13. ed. Porto Alegre AMGH, 2018. 
CONCEIÇÃO, A. R. da; MOTA, M. D. A.; BARGUIL, P. M. Didactic games in teaching and learning Science and Biology: teaching concepts and practices. Research, Society and Development, [S.l.], v. 9, n. 5, p. e165953290, abril. 2020. Disponível em: https://www.rsdjournal.org/index.php/rsd/article/view/3290. Acesso em: 1 apr. 2021.

CONSELHO FEDERAL DE FARMÁCIA. Resolução n. 365 de 2 de outubro de 2001. Dispõe sobre a assistência técnica farmacêutica em distribuidoras, representantes, importadoras e exportadoras de medicamentos, insumos farmacêuticos e correlatos. Brasília (DF): Diário Oficial da União, 2001, Seção 1, p. 324.

CONSELHO FEDERAL DE FARMÁCIA. Conselho Regional de Farmácia, São Paulo, 2016.

CONSELHO FEDERAL DE FARMÁCIA. Resolução n. 365, de 2 de outubro de 2001.

Dispõe sobre a assistência técnica farmacêutica em distribuidoras, representantes, importadoras e exportadoras de medicamentos, insumos farmacêuticos e correlatos. Diário Oficial da União, Brasília (DF); 21 jan 2002; Seção 1:324.

CRISTINE, M. D. Avaliação da experiência de estudantes de farmácia no componente de farmacologia com a utilização da metodologia de aprendizagem baseada em tarefas. Foco, Mogi Guaçu, SP, v. 4, n. 5, p. 89-109, jul/dez. 2013.

FAETI, P. V.; CALSA, G. C. Jogo, competição e cooperação: articulando saberes. In: CONGRESSO NACIONAL DE EDUCAÇÃ̃O, 12., 2015, Curitiba. Anais... Curitiba: EDUCERE, 2015. p. 26-29.

GHEZZI, J. F. S. A et al. Aprendizagem no cenário real na perspectiva docente. In: CONGRESSO IBERO-AMERICANO EM INVESTIGAÇÃO QUALITATIVA, 7., 2018, Fortaleza. Anais... Fortaleza: Investigação Qualitativa em Educação, 2018. p. 629-638 Disponível em: https://proceedings.ciaiq.org/index.php/ciaiq2018/article/view/1690/1642. Acesso em: 04 abr. 2019.

KISHIMOTO, T. M. O brincar e suas teorias. 4. ed. São Paulo: Pioneira Thomson Learning, 2004.

MINAYO, M. C. S. Análise qualitativa: teoria, passos e fidedignidade. Ciência \& Saúde Coletiva, Rio de Janeiro, RJ. v. 17, n. 3, p. 623-626, nov. 2012.

MINAYO, M. C. S. O desafio do conhecimento: pesquisa qualitativa em saúde. 14. ed. São Paulo: Hucitec.

MINAYO, M. C. S.; DESLANDES, S. F.; GOMES, R. Pesquisa social; teoria, método e criatividade. Petrópolis: Vozes, 2016.

MORAN, J. M. Mudar a forma de ensinar e de aprender com tecnologias. Rev Interações Estud Pesqui Psicol, Campo Grande,. v. 5, n. 9, p. 57-72, jan./jun. 2000.

MOREIRA, H. M. et al. O desafio da avaliação no internato da medicina. In: CONGRESSO IBERO-AMERICANO EM INVESTIGAÇÃO QUALITATIVA, 8., 2019, Lisboa. Anais... Lisboa: [s.n.], 2019. p. 516-525.

PIRES, M. R. G. M. et al. Desenvolvimento e validação de instrumento para avaliar a ludicidade de jogos em saúde. Revista da Escola de Enfermagem da USP, São Paulo, SP, v. 49, n. 6, p. 981-990, Dez. 2015.

RANG, H. P. et al. Farmacologia. 8. ed. São Paulo: Koogan, 2016. 
SANTOS, I. et al. Jogos didáticos para o ensino de Zoologia no Ensino Médio: relato de experiência no Município de Ingá-Pb. Braz. J. of Develop., Curitiba, v. 6, n.5, p.27076-27086 may. 2020.

SANTOS, V. R. D. Jogos na escola: os jogos nas aulas como ferramenta pedagógica. Edição. Petrópolis: Vozes, 2014.

SERAFIM, A. R. R. M. et al. Construção de serious games para adolescentes com diabetes mellitus tipo 1. Acta Paul Enferm., São Paulo, v. 32, n. 4, p. 374-81, 2019.

SERIACOPI, R. B. Uma experiência na utilização da webquest na educação profissional do técnico em farmácia. 2006. 103p. Mestrado (Dissertação Ensino em Ciências da Saúde, Universidade Federal de São Paulo, São Paulo, 2006.

SILVA, C. R. MAEP: um método ergopedagógico interativo de avaliação para produtod educacionais informatizados. 2002. Tese de Doutorado não publicada, Universidade Federal de Santa Catarina, Florianópolis, 2002. Recuperado de https://repositorio.ufsc.br/bitstream/handle/123456789/84254/182757.pdf?sequence=1. Acesso em: 29 mar. 2021

SILVA, J. C. S. da.; BIANCO, G. Jogos didáticos: a formação educativa através de uma aprendizagem significativa e um currículo adaptado por projetos. Research, Society and Development, [S. 1.], v. 9, n. 9, p. e820997969, nov. 2020. Disponível em:

https://www.rsdjournal.org/index.php/rsd/article/view/7969. Acesso em: 1 abr. 2021.

SOUSA, F. d. J. et al. Metodologias ativas utilizadas no curso de farmácia. Revista Signos, [S.l.], v. 41, n. 2, p. 290-299, dez. 2020. Disponível em:

http://www.univates.br/revistas/index.php/signos/article/view/2647/1751. Acesso em: 01 abr. 2021.

ZEPPONI, K. M. C.; BRACCIALLI, L. A. D.; PINHEIRO, O. L. Elaboração de jogo educacional na farmacologia: a validação por especialistas, New Trends in Qualitative Research, [S.I.], v. 2, p. 476-489, 2020. Disponível em:

https://publi.ludomedia.org/index.php/ntqr/article/view/112. Acesso em: 01 abr. 2021

ZEPPONI, K. M. C. Jogos educativos: um recurso lúdico de aprendizagem da Farmacologia para ensino técnico. 2020. 177p. Mestrado (Dissertação em Ensino e Saúde) - Faculdade de Medicina de Marília, Marília, 2020.

Recebido em: 15 de junho de 2021.

Aceito em: 10 de agosto de 2021. 